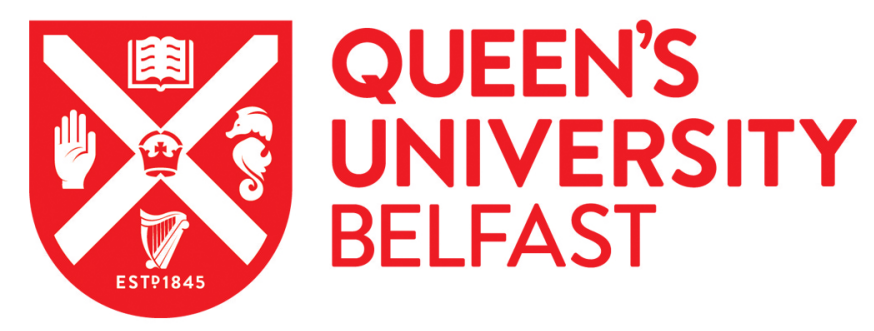

\title{
AMASS: Advanced Manufacturing for the Assembly of Structural Steel
}

Schultz, A. E., Le, J-L., Shemshadian, M. E., Labbane, R., Laefer, D. F., Al-Sabah, S., Hong, L. T., Huynh, M. P., McGetrick, P., Martin, T., \& Matis, P. (2019). AMASS: Advanced Manufacturing for the Assembly of Structural Steel. In ISEC 2019- The Tenth International Structural Engineering and Construction Conference International Structural Engineering and Construction Society. https://www.isec-society.org/ISEC_10/

Published in:

ISEC 2019- The Tenth International Structural Engineering and Construction Conference

Document Version:

Publisher's PDF, also known as Version of record

Queen's University Belfast - Research Portal:

Link to publication record in Queen's University Belfast Research Portal

Publisher rights

Copyright $\odot 2019$ ISEC Press. This work is made available online in accordance with the publisher's policies. Please refer to any applicable terms of use of the publisher.

\section{General rights}

Copyright for the publications made accessible via the Queen's University Belfast Research Portal is retained by the author(s) and / or other copyright owners and it is a condition of accessing these publications that users recognise and abide by the legal requirements associated with these rights.

Take down policy

The Research Portal is Queen's institutional repository that provides access to Queen's research output. Every effort has been made to ensure that content in the Research Portal does not infringe any person's rights, or applicable UK laws. If you discover content in the Research Portal that you believe breaches copyright or violates any law, please contact openaccess@qub.ac.uk. 


\section{AMASS: Advanced Manufacturing for the Assembly of Structural Steel}

Conference Paper · May 2019

CITATION

1

11 authors, including:

Arturo E Schultz

University of Minnesota Twin Cities

206 PUBLICATIONS 1,292 CITATIONS

SEE PROFILE

Ramzi Labbane

University of Minnesota

4 PUBLICATIONS 3 CITATIONS

SEE PROFILE

Some of the authors of this publication are also working on these related projects:

AMASS: Advanced Manufacturing for the Assembly of Structural Steel View project

Reduction of uncertainty through regularized, automated road inspection View project
READS

321
Mohammad Ebrahim Shemshadian

University of Minnesota Twin Cities

17 PUBliCATIONS 58 Citations

SEE PROFILE

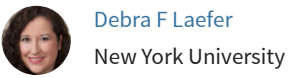

166 PUBLICATIONS 1,628 CITATIONS

SEE PROFILE 


\title{
AMASS: ADVANCED MANUFACTURING FOR THE ASSEMBLY OF STRUCTURAL STEEL
}

\author{
ARTURO E. SCHULTZ ${ }^{1}$, JIA-LIANG LE ${ }^{1}$, MOHAMMAD E. SHEMSHADIAN ${ }^{1}$, RAMZI \\ LABBANE $^{1}$, DEBRA F. LAEFER ${ }^{2,3}$, SALAM AL-SABAH $^{3}$, LINH TRUONG-HONG ${ }^{3}$, MINH \\ HUYNH $^{3}$, PATRICK MCGETRICK ${ }^{4}$, TONY MARTIN ${ }^{4}$, and PANTELIS MATIS ${ }^{4}$ \\ ${ }^{1}$ Dept of Civil, Environmental and Geo-Engineering, University of Minnesota, Twin Cities, \\ Minneapolis, USA \\ ${ }^{2}$ Center for Urban Science and Progress and Dept of Civil and Urban Engineering, New York \\ University, New York, USA \\ ${ }^{3}$ School of Civil Engineering, University College Dublin, Dublin, Ireland \\ ${ }^{4}$ School of Natural and Built Environment, Queen's University Belfast, Belfast, UK
}

\begin{abstract}
This paper describes a collaborative project between the US, Ireland, and Northern Ireland (UK) to investigate advanced manufacturing cutting techniques for the creation of a new class of intermeshed steel connections that rely on neither welding nor bolting. To date, advanced manufacturing equipment has only been used to accelerate traditional processes for cutting sheet metal or other conventional fabrication activities. Such approaches have not capitalized on the equipment's full potential. This project lays the groundwork to transform the steel building construction industry by investigating the underlying science and engineering precepts for intermeshed connections created from precise, volumetric cutting. The proposed system enhances the integration between design, fabrication, installation and maintenance through building information modeling platforms to implement advanced connections. Fully automated, precise, volumetric cutting of open steel sections introduces intellectual challenges regarding the load-transfer mechanisms and failure modes for intermeshed connections. The research activity addresses knowledge gaps concerning the load resistance and design of steel systems with intermeshed connections. Physical tests, finite element simulation and multi-scale modeling are being used to investigate the mechanics of intermeshed connections including stress and strain concentrations, fracture potential and failure modes, and to optimize connection geometry.
\end{abstract}

Keywords: Steel connection, Intermeshed, Plasma, Waterjet, Finite element modeling, Front-intermeshed connection, Side-intermeshed connection.

\section{INTRODUCTION AND CONCEPTS}

Despite field welding and bolting being time-consuming and/or expensive, the steel building market has not developed any new universally applicable structural steel connection systems since before World War II. To achieve improved construction efficiency and heightened material reuse, computer controlled, advanced manufacturing techniques in high-definition plasma, laser and water jet cutting (Figure 1) could be exploited (Ramakrishnan and Rogozinski 1997). This paper envisions the harnessing of those technologies to create an entirely new class of "intermeshed" steel connections. 
Precise cutting of steel makes it possible to create the notches in beam flanges and web that can intermesh with other beam parts or external connectors, like puzzle pieces. This technique could radically change how structural steel is fabricated, assembled, deconstructed, and reused (Perreira et al. 1993). Without relying solely on bolting or welding to assemble a connection in the field, the simplicity and efficiency of the construction process may be significantly improved. To date, this class of fabrication equipment has only been used to accelerate traditional processes for cutting sheet metal or other conventional fabrication activities (e.g., cutting instead of drilling holes). Such approaches have not capitalized on the equipment's full fabrication potential.

Because assembly costs at a construction site are high for welded and bolted connections, the intermeshed connection offers the potential for a lower cost connection, even though manufacturing costs are likely to be higher. There is also the potential for life cycle savings as deconstruction costs would be significantly lower as an intermeshed connection can be designed specifically for disassembly and also for reuse. However, unlike traditional bolted or welded connections, where the industry has more than 100 years of experience, precise cutting of steel for an intermeshed connection is not yet part of the culture or its expectations.

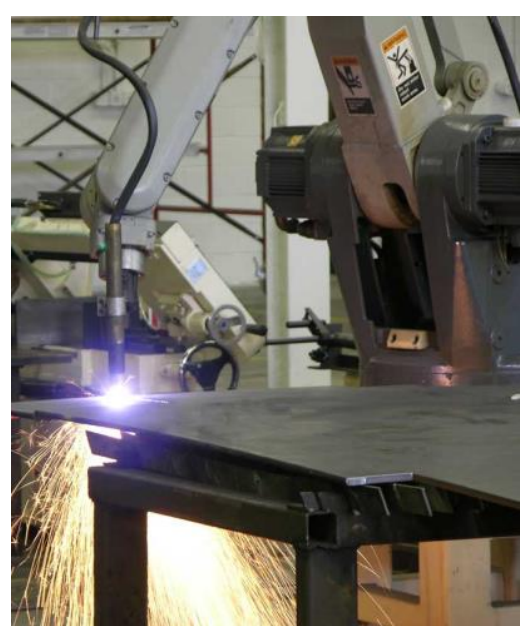

(a) Plasma cutting performed by an industrial robot (Wikipedia 2018a).

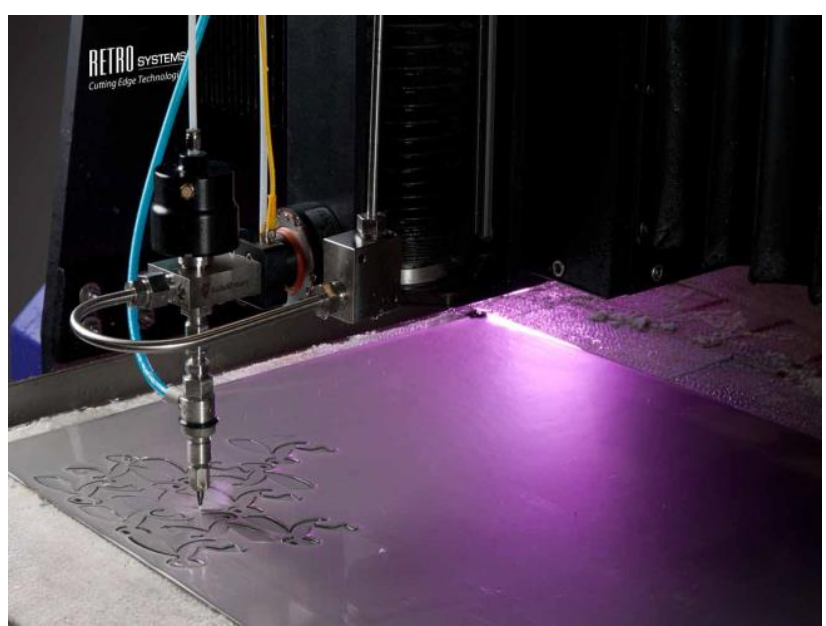

(b) Waterjet computer numerical control cutting machine. (Wikipedia 2018b).

Figure 1. Advanced cutting techniques.

While maintaining the original concept, different alternatives can be developed for the intermeshed connection. A variety of connection details were investigated and different connections were proposed. In this paper, two major ideas for intermeshed connection are presented in the following sections.

\section{FRONT-INTERMESHED CONNECTION}

The very first concept is a relatively simple intermeshed connection called the "FrontIntermeshed Connection" (Al-Sabah and Laefer 2017a). This connection is composed of threedimensional interlocking through the top and bottom flanges and through the web. The flanges carry the tension and compression resulting from the bending moment at the connection, while the web carries the shear force. The connection transfers shear and compression from one beam section to the next through direct contact bearing of multiple, precisely shaped faces (Figure 2). The arrangement is ideally suited for connecting beams at or near ideal inflections points to create 
gravity load framing. For practical use of this new type of connection, understanding its mechanical behavior, especially in terms of the load carrying capacity under mixed mode loading scenarios, will be essential.

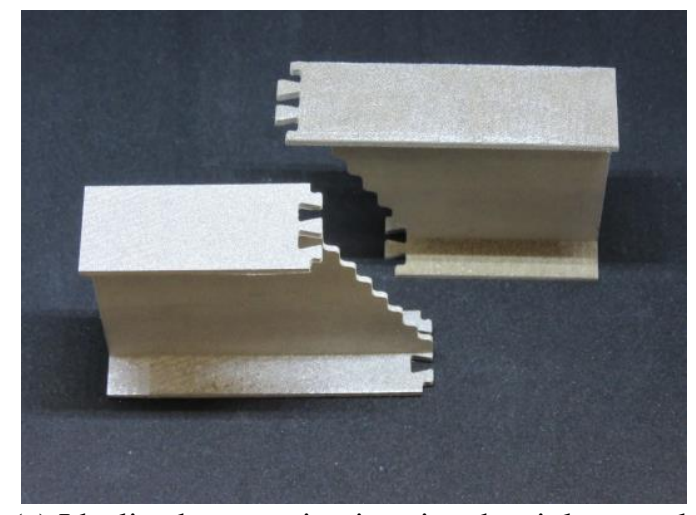

(a) Idealized connection in printed stainless steel.

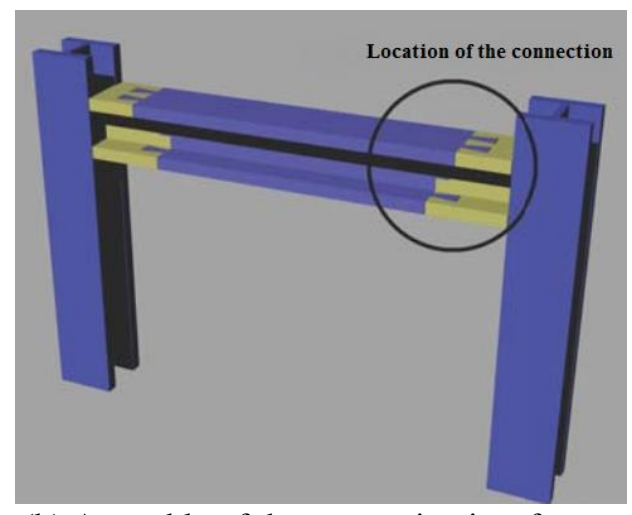

(b) Assembly of the connection in a frame.

Figure 2. Front-intermeshed connection.

Load is transferred between flanges through bearing and friction via the intermeshed teeth of the flanges. The connection has the advantages of simplicity and requires no additional parts to create the flange connection, although a locking mechanism can be added against uplift. However, field-assembled locking connections are unlikely to be able to fully transmit the flexural, axial, and shear capacities of the connected steel sections and may reduce the corresponding stiffness components of a continuous steel member, because of interruptions in the load path.

The stepped web connection allows for easy site assembly, as the middle beam part can be dropped from above, in a method similar to current practice. In Figure $2 b$, the ends shown in yellow are shop welded as stubs to the column. No other welding is required, and bolting is fully avoided in this configuration. The main drawbacks to this type of connection are the tightness of the tolerances and the lack of adjustability in the erection process.

\subsection{Finite Element Analyses in Abaqus}

To better understand how this type of precise interlocking performs structurally, initial lab testing was conducted for two-dimension meshed "fingers" (Matis et al. 2018). Based on the success of those initial tests, a three-dimensional numerical model was created in Abaqus (Abaqus 2013). The finite element analyses were performed under different load combinations to investigate the general behavior, failure modes, and peak capacity of the connection.

Under flexure, the connection shows a uniformly monotonic behavior with a relatively low flexural resistance. Failure occurs when the teeth on one side of the top flange slip out of the sockets on the other side (Figure 3a), so there is no capacity to carry tension force, which means no moment capacity can be developed. Moreover, in the case of combined tension and shear, the presence of the latter causes relative vertical movement between the two sides of the connection and, consequently, the flanges slip out of their intermeshed positions. When this phenomenon happens (Figure 3b), there is no component to resist tension, and the connection fails. 


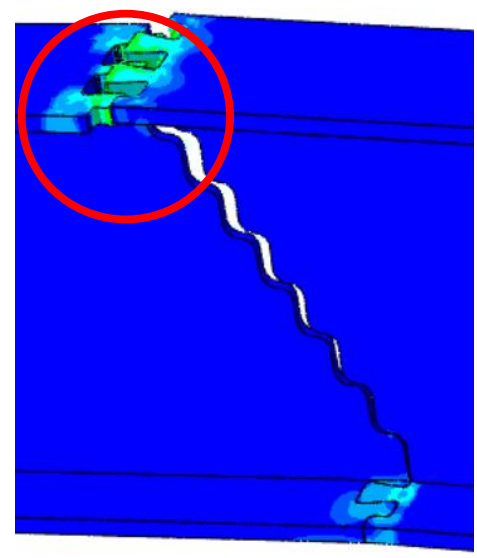

(a) In pure flexure top flange slips out.

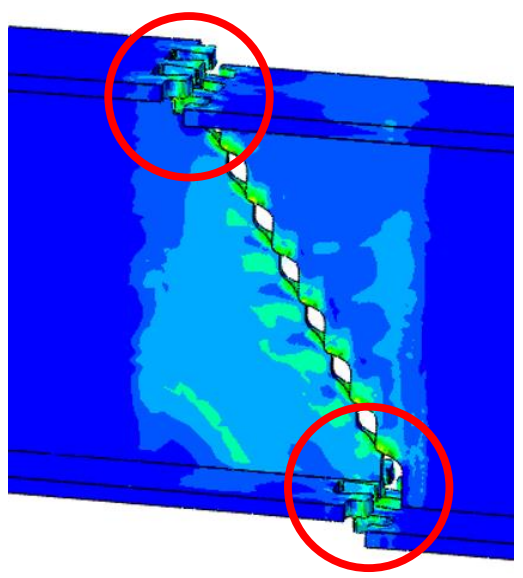

(b) Vertical slip of top and bottom flanges under combined tension and shear.

Figure 3. Performance of the front-intermeshed connection under different load conditions.

\subsection{Connection Characteristics}

Considering the connection configuration and the results of the finite element analyses, the frontintermeshed connection is generating insufficient strength and stiffness for effective use in practice. Therefore, it is helpful to characterize the front-intermeshed connection in terms of its performance characteristics in order to develop strategies for connection improvement.

Following current code standards and based on the results from the finite element studies, the front-intermeshed connection shows limited stiffness, strength, and ductility. So, it is classified as a non-ductile and partially restrained connection (AISC Specification for Structural Steel Buildings 2016, Eurocode 3 2005). This classification is due to the cuts in the flanges which reduce load carrying capacity in tension and, consequently, the moment significantly. Therefore, the front-intermeshed connection is not recommended for use where demands for 1) large moments, 2) large moments in combination with large shears, and 3) axial tension are possible.

\section{SIDE-INTERMESHED CONNECTION}

Given the limitations of the front-intermeshed connection in transferring loads, especially when in the presence of combined loads and strict tolerances, another alternative of the intermeshed connection is proposed (Al-Sabah and Laefer 2017b). The "Side-Intermeshed Connection" utilizes intermeshed external connectors to transfer flange tension and compression forces.

Two different versions of side-intermeshed connection were developed. The "original conception" (Figure 4) sought to meet the original goals of requiring no welding nor bolting at all, while maximizing erection speed and construction tolerance. Meanwhile, the second version (Figure 5) was modified for greater acceptance in the construction industry and includes minor bolting. This paper focuses on the modified version of the side-intermeshed connection.

In this connection, flange edges are cut to create a set of tooth-shape notches (i.e. "teeth"). To connect different sides of the beam, an angle is used on each edge with horizontal holes which match the teeth (see Figure 5). Having the beam flanges connected, the section will be able to transfer moments via the connector angles. However, for shear transfer, a pair of regular shear plates are bolted to the beam web. 


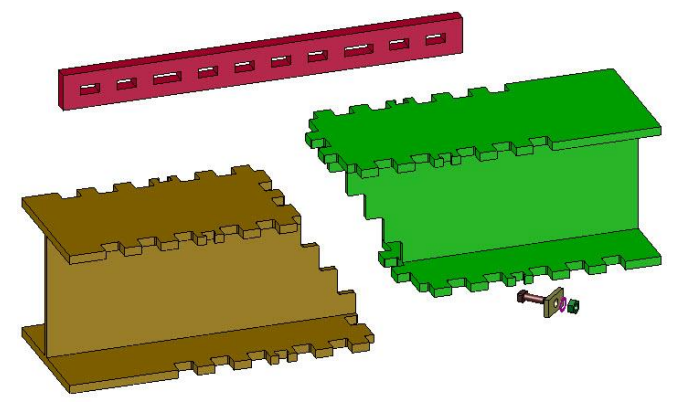

(a) 3D Exploded view.

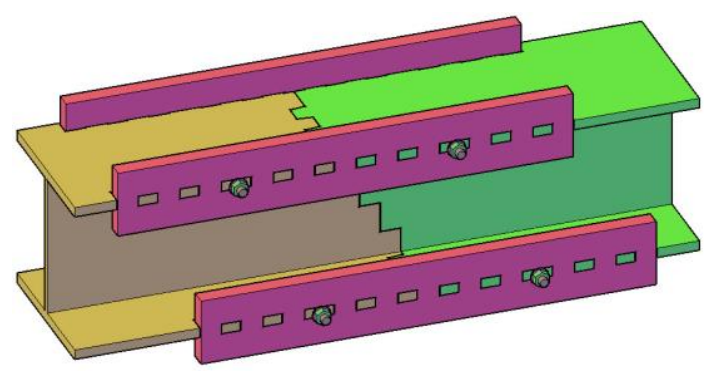

(b) 3D View of assembled connection.

Figure 4. Side-intermeshed connection (original conception).

A new design approach was adopted based on the concept of "Capacity Design" and the requirements of the current US steel design standard (AISC Steel Construction Manual 2017). In this approach, the angles are designed for applied loads (obtained from elastic analysis). Subsequently, the teeth are designed for maximum expected forces based on connector angle capacity. Using "Capacity Design" assures that failure occurs in the angles rather than the teeth. Such a mechanism is desirable since the replacement of the angles is easy and fast following a case of damaging overload. Given the number of variables needed to define connection resistance, an iterative approach for the proportioning of the elements is needed.

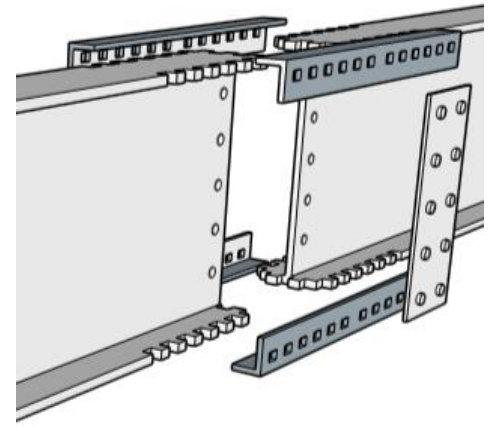

(a) 3D Exploded view.

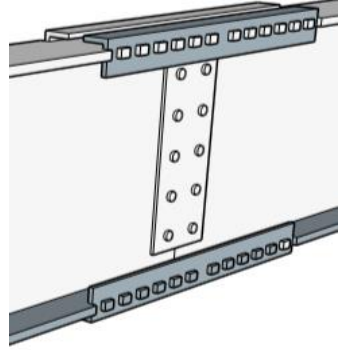

(b) 3D View of assembled connection.

Figure 5. Side-intermeshed connection (modified version).

The side-intermeshed connection allows larger tolerances and easier fabrication, which leads to a better potential for wider accepted in practice. However, one potential concern related to this connection is the stress concentration at the sharp corners of the angle holes. Depending on the length-to-width ratio of the angle holes, previous studies have shown that the stress concentration factor can be up to 5 (Sikora 1973) which can result in pre-mature rupture. To avoid any undesirable failure modes, circular holes were added to the sharp corners in the angle holes. A finite element model proved the effectiveness of such a change by reducing the stress concentration factor to 1.7. Figure 6 shows the configuration of the hole and the resulting stress. Further study of the side-intermeshed connection is ongoing, including cohesive modeling of the connection to enable efficient analysis, and experimental verification. 


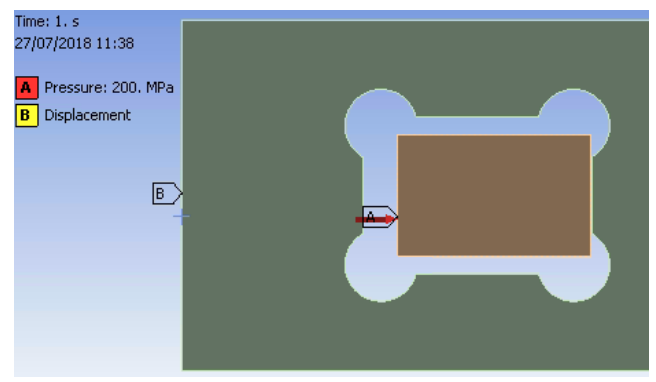

(a) Load and boundary conditions.

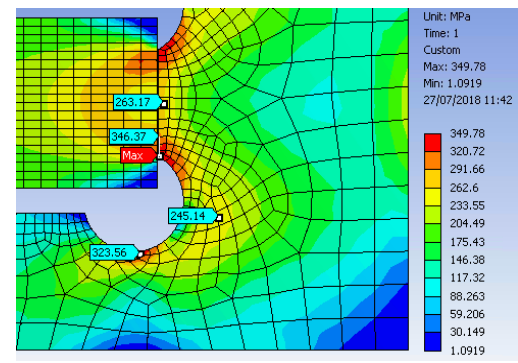

(b) Equivalent stress around the corner.

Figure 6. Finite element analysis on the effect of the shape on the stress concentration around the hole.

\section{CONCLUSIONS}

This study analyzed a radically new connection for structural steel members, which uses multidegrees of freedom, volumetric cutting to drastically reduce fabrication costs and vastly simplify and accelerate erection by avoidance of supplementary materials and methods. Based on this concept, two different alternatives of intermeshed connections were proposed and investigated.

Results from finite element modeling in Abaqus showed that the front-intermeshed connection exhibits excellent shear resistance even in the presence of moment or axial force. On the other hand, axial or flexural behavior is sensitive to the relative position of the flanges. The presence of shear can make the case more critical as it makes the flanges slip out, and the connection would lose the ability to hold together. Based on flexural characteristics, the frontintermeshed connection shows low stiffness and resistance rendering it a simple connection.

In keeping with the intermeshed connection concept, another alternative is proposed that eliminates the negative aspects of the front-intermeshed connection. The resulting sideintermeshed connection offers larger load capacity potential and larger erection tolerances. A special detail at the angle holes was adopted to avoid stress concentration.

\section{References}

Abaqus, 6.13 Manual, SIMULIA, Providence, RI. 2013.

AISC Specification for Structural Steel Buildings, American Institute for Steel Constructions, 2016.

AISC Steel Construction Manual, American Institute for Steel Constructions. 2017.

Al-Sabah, A., and Laefer, D., GB Patent Application No 1718744.4, 2017a.

Al-Sabah, A., and Laefer, D., GB Patent Application No 1718746.9, $2017 \mathrm{~b}$.

Eurocode 3: Design of Steel Structures - Part 1-8: Design of Joints, Eurocode, 2005.

Matis, P., Martin, T., McGetrick, P. J., and Robinson, D., The Effect of Frictional Contact Properties on Intermeshed Steel Connections, CERAI 2018 Dublin Ireland, Paper 199, 2018.

Perreira, N. D., Fleischman, R. B., Viscomi, B. V, and Lu, L.-W., Automated Construction and ATLSS Connections; Development, Analysis, Experimentation, and Implementation of ATLSS Connections for Automated Construction, ATLSS Reports, Lehigh University, 1993.

Ramakrishnan, S., and Rogozinski, M. W., Properties of Electric Arc Plasma for Metal Cutting, Journal of Physics D: Applied Physics, 30(4), 636-644, 1997.

Sikora, J. A., Summary of Stress Concentrations in the Vicinity of Openings in Ship Structures, Naval Ship Research and Development Center, Report 3889, 1973.

Wikipedia, retrieved from https://en.wikipedia.org/wiki/Plasma_cutting, 2018a.

Wikipedia, retrieved from https://en.wikipedia.org/wiki/Water_jet_cutter, 2018b. 